\title{
Study on the Galvanic Corrosion Behavior of Q235 /Ti Couple in Artificial Seawater
}

\author{
Xiaodong Zhang ${ }^{1}$, Xiaoqing D ${ }^{2, *}$ Shaowei Feng ${ }^{1}$, Zhao Zhang ${ }^{2, *}$ \\ ${ }^{1}$ MIUR, Naval University of Engineering, Wuhan 430033, People's Republic of China \\ ${ }^{2}$ Department of Chemistry, Zhejiang University, Hangzhou 310027, People's Republic of China \\ *E-mail: amyzju88@163.com; eaglezzy@zju.edu.cn
}

doi: $10.20964 / 2018.05 .82$

Received: 26 January 2018 / Accepted: 27 February 2018 / Published: 10 April 2018

\begin{abstract}
The corrosion behavior of Q235/Ti galvanic couple in the artificial seawater has been investigated by using electrochemical impedance spectroscopy (EIS), electrochemical noise (EN) and scanning electron microscope (SEM) techniques. The results show that the whole corrosion process of Q235/Ti galvanic couple should be divided into three stages by using EIS technique, whereas the same corrosion process can only be divided into two stages by using EN technique. There exists good relationship between the charge transfer resistance $\left(R_{\mathrm{ct}}\right)$ obtained from EIS technique and the corrosion index $S_{\mathrm{E}}$ obtained by EN technique. EN technique is more sensitive to pitting corrosion than EIS technique, and can be used to distinguish the main corrosion type.
\end{abstract}

Keywords: Q235/Ti couple; Galvanic corrosion; Electrochemical impedance spectroscopy; Electrochemical noise; Maximum entropy method

\section{FULL TEXT}

(C) 2018 The Authors. Published by ESG (www.electrochemsci.org). This article is an open access article distributed under the terms and conditions of the Creative Commons Attribution license (http://creativecommons.org/licenses/by/4.0/). 